$\mathbb{\Psi}$ periodica polytechnica

Civil Engineering

$53 / 2(2009) 53 \quad 60$

doi: 10.3311/pp.ci.2009-2.01

web: http://www.pp.bme.hu/ci

(c) Periodica Polytechnica 2009

RESEARCH ARTICLE

\section{Long-term analysis of bending moment resistance on pre-cast concrete beams}

\author{
Kálmán Koris / István Bódi
}

Received 2008-12-16, revised 2009-03-24, accepted 2009-04-27

\begin{abstract}
Durability design of structures is an important part of the design process. A possible method for the durability design is the probabilistic approach considering changes of structural resistance and the load effect during a certain time period. In order to determine stochastic parameters of structural resistance as a function of time, deterioration of materials and the decrease of structural sizes due to environmental effects must be predicted. This paper is mainly focusing on the analysis of the bending moment resistance of pre-cast concrete beams as a function of time. The effect of creep, shrinkage, relaxation, carbonation induced corrosion and deterioration of cross-sectional sizes on the mean value and standard deviation of bending moment resistance were considered. The performed calculation method is illustrated by numerical example on a pre-cast, prestressed concrete beam. In case of the presented beam, the mean value of bending moment resistance decreases 4-6\% and its standard deviation increases 200-350\% after 100 years depending on the relative ambient humidity. Results concerning mean value and standard deviation of structural resistance can be used for the purposes of probabilistic durability design. Considering the same safety level as in Eurocode 2, the introduced probabilistic design method delivers about 10\% higher load carrying capacity as the application of relevant Eurocode 2 standard in case of the presented beam.
\end{abstract}

\section{Keywords}

Durability $\cdot$ safety $\cdot$ rheological effects $\cdot$ bending moment resistance $\cdot$ pre-cast concrete $\cdot$ prestressed concrete

\section{Kálmán Koris}

Department of Structural Engineering, BME, Múegyetem rkp. 3. Budapest, H1521, Hungary

e-mail: koris@vbt.bme.hu

\section{István Bódi}

Department of Structural Engineering, BME, Múegyetem rkp. 3. Budapest, H1521, Hungary

e-mail: bodi@vbt.bme.hu

\section{Introduction}

The importance of durability became and important aspect of the design process recently [3]. In order to perform proper durability-design, the rheological changes of material properties and the decrease of structural sizes due to environmental effects must be modelled, and these changes must be considered during the determination of structural resistance. Rheological processes are usually affected by the environmental conditions, such as average temperature, ambient humidity and presence of aggressive agents, as well as by the initial material properties of the structure. The aim of the research was, on one hand, to determine the decrease of load carrying capacity in time due to slow deformations and aging of materials, on the other hand to calculate the probability of failure of the structure by means of varying load carrying capacity and external loads. The relationship between elapsed time and the probability of failure was finally used for the purposes of durability design of appropriate structures. The probability of failure was determined by stochastic finite element method (SFEM). The details of appropriate stochastic finite element formulation were deducted in previous part of the research [8]. In frames of this paper, the determination of the load carrying capacity (mean value and standard deviation) as a function of time is introduced. During the research, bending moment capacity of pre-cast, prestressed concrete floor beams was analysed. These types of beams are used for the construction of floors in houses or industrial buildings and they are usually not subjected to aggressive environmental effects or freeze-thaw actions, therefore these effects were neglected during the analysis. Creep and shrinkage of concrete, relaxation and carbonation induced corrosion of steel bars and tendons as well as the decrease of cross-sectional dimensions were considered. The bending moment resistance of pre-cast concrete members was evaluated as a function of time elapsed since manufacture and the relative ambient humidity. The humidity was selected for a variable parameter of the calculations since it is one of the most important factors to influence the process of carbonation and its value can be measured or controlled during the service life of the structure.

The probabilistic analysis of structures has an extensive liter- 
Tab. 1. List of tested materials and prestressed beams

\begin{tabular}{|c|c|c|c|}
\hline \multicolumn{2}{|c|}{ Type of material or beam } & \multirow{2}{*}{$\begin{array}{c}\text { Manufacturer } \\
\text { M1 }\end{array}$} & \multirow{2}{*}{$\begin{array}{l}\begin{array}{l}\text { Number of tested/measured } \\
\text { specimens }\end{array} \\
54\end{array}$} \\
\hline \multirow{7}{*}{ Concrete } & C40/50, 28 days & & \\
\hline & C50/60, 28 days & M1 & 42 \\
\hline & C30/37, 7 days & M2 & 9 \\
\hline & C35/45, 7 days & M2 & 12 \\
\hline & C40/50, 7 days & M2 & 54 \\
\hline & C60/75, 7 days & M2 & 3 \\
\hline & C50/60, 28 days & M3 & 636 \\
\hline \multirow{12}{*}{ Steel bar } & BHB55.50, Ф6 & M4 & 3 \\
\hline & BHB55.50, Ф 8 & M4 & 4 \\
\hline & BHB55.50, Ф12 & M4 & 5 \\
\hline & BST $500 \mathrm{KR}, \Phi 8$ & M5 & 52 \\
\hline & BST $500 \mathrm{KR}, \Phi 10$ & M5 & 28 \\
\hline & BST 500 KR, Ф12 & M5 & 5 \\
\hline & $\mathrm{B} 60.50, \Phi 12$ & M6 & 20 \\
\hline & B60.50, Ф14 & M6 & 15 \\
\hline & B60.50, Ф16 & M6 & 20 \\
\hline & B60.50, Ф20 & M6 & 89 \\
\hline & В60.50, Ф25 & M6 & 45 \\
\hline & В60.50, Ф28 & M6 & 5 \\
\hline \multirow[b]{2}{*}{ Prestressing tendon } & Fp 38/1770-R2 & M7 & 3 \\
\hline & Fp 100/1770-R2 & M7 & 20 \\
\hline \multirow{6}{*}{ Prestressed beam } & EE-42 & M2 & 7 \\
\hline & EE-48 & M2 & 11 \\
\hline & EE-54 & M2 & 5 \\
\hline & EE-66 & M2 & 4 \\
\hline & 4000 & M1 & 11 \\
\hline & 4700 & M1 & 10 \\
\hline
\end{tabular}

ature, however, most of these contributions deal with the mathematical formulation and solution of the problem only. Numerical example to the calculation of structures by probabilistic approach can be found much less frequently. Some of the contributions containing numerical examples for the probabilistic analysis of structures are listed below. An early approach by J. Almási [1] included probabilistic method for the analysis of reinforced and prestressed concrete structures combining finite element method (FEM) with Monte-Carlo simulation (MCS). He considered random structural geometry and material properties as well as non-linear behaviour of materials and steel to concrete interaction. W. K. Liu, G. H. Besterfield T. Belytschko used SFEM for the analysis of a cantilever beam subjected to large deflection. They considered Saint Venant-Kirchoff model for nonlinear elasticity, random load, random Young's modulus as well as random cross-sectional height [12]. J. Eibl and B. Schmidth-Hurtienne demonstrated the use of SFEM on a twospan reinforced concrete beam and on a reinforced column [6]. They considered random cross-sectional sizes, material properties and loads during the calculations. Non-linear behaviour for the concrete and steel was assumed. W. B. Krätzig and Y. S. Petryna introduced a method for structural damage and lifetime estimate by non-linear finite element simulation [10]. The method is analyzing the dynamic response of reinforced concrete structures by the evaluation of the damage process. Elastic- plastic behaviour of materials was taken into consideration including damage components for the analysis. Random quantities for geometrical sizes, material properties and loads were used. Changes of material properties were taken into account by different damage states. The use of the method was demonstrated on a reinforced concrete frame and a reinforced concrete slab bridge. F. Biondini, D. M. Frangopol and P. G. Malerba investigated the time evolution of the uncertainty effects associated with the different parameters defining the probabilistic structural performance of two existing cable-stayed bridges [4]. Random material properties and geometrical sizes, nonlinear material behaviour and the deterioration of materials due to the diffusion of an aggressive agent were considered during the analysis. Lógó et. al. introduced a stochastic optimal topology design method with iterative solution technique for the topology design procedure of structures [13, 14]. E. Posek was using an algorithm of structural reliability evaluation based on design sensitivity analytical approach for the investigation of a reinforced concrete nuclear containment vessel [18].

\section{Calculation method}

Initial values of input parameters (strength of materials, geometry of the structure) were determined from material test results and measurements on existing pre-cast concrete beams. Products of 7 different Hungarian companies were considered 
Tab. 2. Possible deterioration processes of reinforced concrete structures

\begin{tabular}{cc}
\hline Type of deterioration & Limit states \\
\hline Carbonation induced corrosion & $\begin{array}{c}\text { depassivation } \\
\text { corrosion induced cracking } \\
\text { corrosion induced spalling } \\
\text { corrosion induced collapse }\end{array}$ \\
\hline Chloride induced corrosion & $\begin{array}{c}\text { depassivation } \\
\text { corrosion induced cracking } \\
\text { corrosion induced spalling } \\
\text { corrosion induced collapse }\end{array}$ \\
\hline Frost induced internal damage & local loss of mechanical properties \\
& cracking \\
\hline Frost and salt induced surface scaling & scaling and loss of cross section \\
\hline
\end{tabular}

during the analysis (company names are not mentioned upon request so they will be just referred as M1, M2, M3, etc.). Material tests and geometrical measurements were carried out at the laboratories of these companies. Concrete strength was obtained from uniaxial compression tests carried out on $150 \times 150 \times 150 \mathrm{~mm}$ cubes. Test results of altogether $810 \mathrm{spec}-$ imens were considered. Laboratory tensile tests were carried out to determine material properties of reinforcing steel. Modulus of elasticity, strength and ultimate strain of different steel bar types were measured. Steel products of 3 different manufacturers were analysed on altogether 291 specimens. Prestressing strands were also analysed by laboratory tensile tests. The modulus of elasticity, strength and the ultimate strain were measured on 23 specimens. The numbers of tested steel bar specimens in case of different steel grades and different manufacturing companies are listed in Tab. 1. Materials from different manufacturers were evaluated separately so measured data concerning a given material and strength class can be considered homogenous.

Due to different deterioration processes, the input parameters described above are not constant but they are changing in time. Possible deterioration mechanisms of reinforced concrete structures are presented on Tab 2 [17].

In frames of the research, the collapse of the structure due to carbonation induced corrosion was analysed. The process of carbonation is getting slower as the concrete strength is increasing. For concrete classes higher than C40/50 (which is common for pre-cast concrete members) the carbonation induced corrosion first evolves after 40-50 years only. However pre-cast concrete beams can also used for structures with a life-span of 50-150 years (e.g. bridges) so it is important to consider the effect of carbonation as well. Determination method of timedependent parameters is described below.

\subsection{Effective prestressing stress}

The initial value of prestressing stress $\left(\sigma_{p 0}\right)$ is usually determined so that plastic deformations of tendons are avoided [7]. The usual value for this stress is around 1200-1300 N/mm $\mathrm{m}^{2} \mathrm{de}-$ pending on the actual conditions. For the analysed beam types $\sigma_{p 0}=1300 \mathrm{~N} / \mathrm{mm}^{2}$ was used by the manufacturer. The loss of prestressing stress was determined according to the relevant Eurocode 2 standard [5], considering the effect of creep, shrinkage, relaxation and the elapsed time since manufacture $(t)$. The shrinkage strain and the creep coefficient were, of course functions of the relative ambient humidity $(R H)$. Depending on the humidity level, the stress loss after 100 years was about $10-15 \%$ in case of the examined beams.

\subsection{Geometry of the cross-section}

Change of the mean value of cross-sectional sizes (height, width, effective depth of steel bars and tendons) is usually insignificant in case of concrete structures, thus a constant value was assumed during the calculation of the mean value of bending moment resistance. Change of the standard deviation of structural geometry was, however considered during the subsequent probabilistic durability analysis [8].

\subsection{Strength of materials}

The strength of concrete, steel bars and prestressing tendons are the most important material properties to affect the structural resistance in ultimate limit state [16]. Mean value of concrete strength reaches its maximum in about 2 years after manufacturing because of afterhardening, later this value starts to decrease due to fatigue of the material. Same decrease can be observed in case of mean values of steel bar and prestressing tendon strengths. This effect can be described by the following equation [16]:

$$
f_{m}(t)=f_{m 0} \cdot \beta(t)
$$

where $f_{m}(t)$ is the mean value of strength at the time $t, f_{m 0}$ is the initial mean value of strength and $\beta(t)$ is the function describing the decrease of the strength. Assuming a time period $t_{0}$ in which the strength of the material decreases to zero, $\beta(t)$ can be expressed by the first few terms of its Taylor-series [16]:

$$
\beta(t) \cong 1-\frac{1}{3}\left(\frac{t}{t_{0}}\right)^{2}-\frac{1}{3}\left(\frac{t}{t_{0}}\right)^{3}-\frac{1}{3}\left(\frac{t}{t_{0}}\right)^{4}
$$

The value of $t_{0}$ can usually vary between 50 and 1000 years depending on the type of material, on the conditions of usage and on the rate of maintenance. During the analysis, $t_{0}=500$ years was assumed. Standard deviation of material strength also changes during time. This effect can be described by the Gaussprocess [16]:

$$
s_{f}(t)=\sqrt{s_{f 0}^{2} \cdot\left[1+b\left(\frac{t}{t_{0}}\right)^{k}\right]}
$$


where $s_{f}(t)$ is the standard deviation of strength at the time $t$, $s_{f 0}$ is the initial value of standard deviation, $b$ and $k$ are constants describing the increase of standard deviation. In case of concrete, the values $b=1.5$ and $k=1$ were used, for steel bars and tendons the values $b=1.4$ and $k=1.2$ were applied during the analysis based on the recommendations of [16]. The exact values of constants $b$ and $k$ can be usually determined empirically by observations and measurements on existing beams. Standard deviation of material strength was considered during the subsequent probabilistic durability analysis [8].

\subsection{Carbonation induced corrosion of steel bars and ten- dons}

Decrease of steel bar and tendon diameter due to carbonation induced corrosion was also considered in the calculation. The carbonation depth at the time $t$ can be expressed from the following equation [17]:

$$
x_{c}(t)=\sqrt{2 \cdot k_{e} \cdot k_{c} \cdot\left(k_{t} \cdot R_{A C C, 0}^{-1}+\varepsilon_{t}\right) \cdot C_{s}} \cdot \sqrt{t} \cdot W(t)
$$

where $k_{e}$ is the environmental function, $k_{c}$ is the execution transfer parameter, $k_{t}=1.25$ is the regression parameter, $R_{A C C, 0}^{-1}$ is the inverse effective carbonation resistance of concrete derived from accelerated test (ACC), $\varepsilon_{t}=315.5\left(\mathrm{~mm}^{2} /\right.$ years $) /\left(\mathrm{kg} / \mathrm{m}^{3}\right)$ is the error term considering inaccuracies which occur conditionally when using ACC test method, $C_{s}$ is the $\mathrm{CO}_{2}$ concentration and $W(t)$ is the weather function that takes the effect of rain events on the concrete carbonation into account. The environmental function can be expressed as a function of the relative humidity of the carbonated layer. During the analysis, the relative humidity of the carbonated layer was assumed to be same as the relative ambient humidity $(R H)$, which is one of the most important factors to influence the process of carbonation and its value can be measured or controlled during the service life of the structure. The execution transfer parameter was calculated by the consideration of a curing period $t_{c}=7$ days. The inverse effective carbonation resistance of concrete can be obtained from the ACC test. There was no test data available for the analysis, so recommended values from Tab. 3 were used.

The cement type CEM I $42.5 \mathrm{R}$ and the value $w / c=0.4$ were assumed in the calculations. For the calculation of the $\mathrm{CO}_{2}$ concentration, the $\mathrm{CO}_{2}$ concentration of the atmosphere and the $\mathrm{CO}_{2}$ concentration due to emission sources were considered. The actual $\mathrm{CO}_{2}$ content in the atmosphere has been detected to be in a range of $350-380 \mathrm{ppm}$. This corresponds with a $\mathrm{CO}_{2}$ concentration of 0.00057 to $0.00062 \mathrm{~kg} / \mathrm{m}^{3}$. The increase of $\mathrm{CO}_{2}$ concentration is about $1.5 \mathrm{ppm}\left(1.628 \cdot 10^{-6} \mathrm{~kg} / \mathrm{m}^{3}\right)$ per year according to [17]. The additional $\mathrm{CO}_{2}$ concentration due to emission sources was $C_{s, e m i}=0.00082 \mathrm{~kg} / 3$. According to these values, the $\mathrm{CO}_{2}$ concentration was calculated from the equation below:

$$
C_{s}(t)=0.00139+t \cdot 1.628 \cdot 10^{-6}\left[\mathrm{~kg} / \mathrm{m}^{3}\right]
$$

where $t$ is the elapsed time in years. Assuming interior structural elements (no rain effect), a constant weather function $\mathrm{W}(t)=1$ was used in the analysis.

After the concrete cover $(a)$ is completely carbonated, steel bars and tendons may begin to corrode. Using equation (4), the time of carbonation $\left(t_{c}\right)$ of concrete cover can be calculated from the following equation:

$$
a=x_{c}\left(t_{c}\right)
$$

The process of corrosion is an electrochemical reaction. The relation between the diameter of rusted steel bar and corrosion time under normal atmospheric conditions is outlined as [19]:

$$
\phi(t)=\phi_{0}-0.0232 \int_{0}^{t} i_{c o r r}(t) d t
$$

where $t$ is the time of corrosion measured from the time point $t_{c}$, $\phi_{0}[\mathrm{~mm}]$ is the diameter of steel bar before corrosion and $i_{\text {corr }}(t)$ represents current corrosion density at time $t$.

$$
i_{\text {corr }}(t)=37.8 \frac{(1-w / c)^{-1.64}}{a} \cdot 0.85 \cdot t^{-0,29}
$$

where $w / c$ is the water/cement ratio of the concrete. The area of steel bars or tendons in a certain point of time can be obtained from:

$$
A_{s, p}(t)=\phi(t)^{2} \cdot \frac{\pi}{4}
$$

where $t$ is the elapsed time since the time point $t_{c}$ as described above. Steel bars are usually closer to the surface of the concrete than the prestressing tendons; therefore they start to corrode earlier.

\subsection{Determination of the structural resistance}

In frames of the research, the failure probability of structural members was evaluated. The failure probability can be usually obtained by means of the first two parameters of the distributions of structural resistance and acting loads [2, 8, 11, 15]. Mean value and standard deviation of structural resistance were calculated by stochastic finite element method [2,6, 9, 11] while the distribution of load effect was calculated according to [16].

Mean value of structural resistance in case of the analysed prestressed concrete beams was determined by finite element method considering non-linear behaviour of concrete and steel [8, 9]. Mean values of input parameters described above were used for the analysis. Shear deformations were neglected in the calculation since they are significantly lower than the flexural deformations in case of reinforced concrete. The method of load increments was used and for each load increment, the chord of the stiffness matrix was evaluated. Failure of the structure was specified by a damage indicator, consisting of the eigenvalue of stiffness matrix in case of structural damage and the eigenvalue of current stiffness matrix at the given load level.

The scatter of structural resistance was evaluated by means of scatter of the stiffness matrix $(\mathbf{K})$. Assuming that $\mathbf{K}$ is a function 
Tab. 3. Effective carbonation resistance of concrete obtained from accelerated test. (Notations: Ihomogeneous cement, III - fly ash cement, $R$ - rapid cement, FA - fly ash, SF - silica fume)

\begin{tabular}{ccccccc}
\hline$R_{A C C, 0}^{-1}\left[10^{-11}\left(\mathrm{~m}^{2} / \mathrm{s}\right) /\left(\mathrm{kg} / \mathrm{m}^{3}\right)\right]$ & \multicolumn{7}{c}{ w/c ratio } \\
\hline Cement type & 0.35 & 0.40 & 0.45 & 0.50 & 0.55 & 0.60 \\
\hline CEM I 42.5 R & - & 3.1 & 5.2 & 6.8 & 9.8 & 13.4 \\
\hline CEM I 42.5 R + FA (k=0.5) & - & 0.3 & 1.9 & 2.4 & 6.5 & 8.3 \\
\hline CEM I 42.5 R + SF $(\mathrm{k}=2.0)$ & 3.5 & 5.5 & - & - & 16.5 & - \\
\hline CEM III/B 42.5 & - & 8.3 & 16.9 & 26.6 & 44.3 & 80.0 \\
\hline
\end{tabular}

of an $\alpha$ random input variable, its variation $(\delta \mathbf{K})$ can be approximately expressed by the first term of its Taylor's series:

$$
\delta \mathbf{K}=\frac{\partial \mathbf{K}}{\partial \alpha} \delta \alpha
$$

where $\delta \alpha$ is the variation of $\alpha$. This approximation is reasonable if the variation of the stiffness matrix is less than about $15 \%$. According to the results of the calculations, this limitation does not apply to analysed prefabricated members. Using equation (10) the covariance matrix of structural resistance can be expressed in the following form [6],9]:

$\mathbf{C}_{q}=\delta \mathbf{q}_{F} \cdot \delta \mathbf{q}_{F}^{T}=\mathbf{K}_{F}^{-1} \cdot \frac{\partial \mathbf{K}}{\partial \alpha} \cdot \mathbf{u} \cdot \delta \boldsymbol{\alpha} \cdot \mathbf{C}_{\rho} \cdot \delta \boldsymbol{\alpha}^{T} \cdot \mathbf{u}^{T} \cdot \frac{\partial \mathbf{K}^{T}}{\partial \alpha} \cdot \mathbf{K}_{F}^{-T}$

where $\delta \alpha$ includes the standard deviations of random input variables (structural dimensions and material properties) and $\mathbf{C}_{\rho}$ is the correlation matrix. The correlation between different elements was described by an exponentially decaying function of the distance between two elements and the length of correlation. The standard deviation of structural resistance can be obtained as square root of the diagonal elements in the covariance matrix $\mathbf{C}_{q}$. Using equation (11), the standard deviation of structural resistance can be evaluated on structural level instead of crosssectional level.

\section{Results of the analysis}

Six different pre-cast concrete beam types (EE-42, EE-48, EE-54, EE-66, 4000, 4700) were analysed in frames of the research. Beam type "EE" is manufactured by manufacturer M2. These types of beams are often used for the construction of roofs in residential houses. Beam type " 4000 " is a $28.782 \mathrm{~m}$ long and $1.45 \mathrm{~m}$ high prestressed main girder that is used for the construction of industrial buildings and halls. Results of the numerical analysis on the long-term behaviour of bending moment resistance are demonstrated in case the beam type " 4700 " which is manufactured by M1 manufacturer. It is an $L_{b}=6.06 \mathrm{~m}$ long and $h=0.749 \mathrm{~m}$ high prestressed concrete girder that is used for supporting the main girders in industrial buildings and halls. Cross-section and reinforcement of the beam is presented in Fig. 1. The upper flange of the beam is inclined so the crosssection is not symmetrical; however, the beam can be loaded in special joints only to assure proper vertical load transfer. Height and width of the cross-section as well as the length were measured on 10 beams after manufacture (see Tab. (4).
Tab. 4. Measured geometrical sizes of beam " 4700 "

\begin{tabular}{cccc}
\hline Specimen number & $\mathrm{Lb}[\mathrm{m}]$ & $\mathrm{b}[\mathrm{m}]$ & $\mathrm{h}[\mathrm{m}]$ \\
\hline 1 & 6,060 & 0,355 & 0,747 \\
\hline 2 & 6,055 & 0,350 & 0,750 \\
3 & 6,055 & 0,350 & 0,750 \\
4 & 6,065 & 0,350 & 0,755 \\
5 & 6,060 & 0,350 & 0,755 \\
6 & 6,055 & 0,350 & 0,755 \\
7 & 6,065 & 0,350 & 0,747 \\
8 & 6,055 & 0,350 & 0,750 \\
9 & 6,055 & 0,350 & 0,752 \\
10 & 6,055 & 0,350 & 0,755 \\
Mean value & 6,058 & 0,351 & 0,752 \\
\hline Relative standard deviation [\%] & 0,070 & 0,451 & 0,435 \\
\hline
\end{tabular}

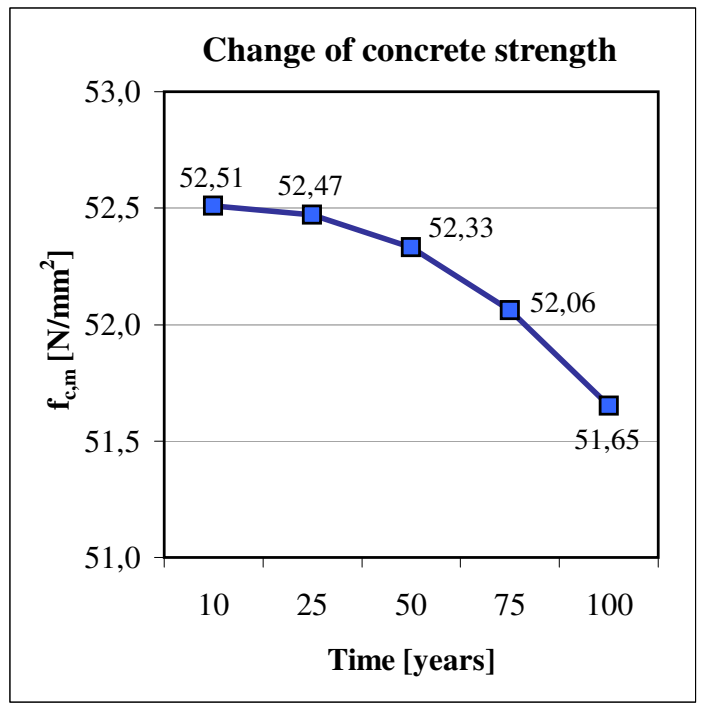

Fig. 2. Change of the mean value of concrete strength in time

Material properties were derived from the material test results described before. According to the class of utilized materials, the following strength values were used for the calculation: $f_{c, m}=52.5 \mathrm{~N} / \mathrm{mm}^{2}, v_{f c}=6.4 \%, f_{s, m}=653.4 \mathrm{~N} / \mathrm{mm}^{2}$, $v_{f s}=2.19 \%, f_{p, m}=1930 \mathrm{~N} / \mathrm{mm}^{2}$ and $v_{f p}=1.4 \%$. Mean values of cross-sectional dimensions (see Tab. 4) and material properties were used as input parameters for the FEM analysis while relative standard deviations of the input parameter were used for the determination of the scatter of bending moment resistance.

Change of the mean value of concrete strength in time is presented in Fig. 2 Strength of steel bars and prestressing tendons in function of time are presented in Fig. 3. After 100 years, the decrease of strength is about $1.7 \%$ for all materials accord- 
Fig. 1. Side view and cross section of beam type "4700"
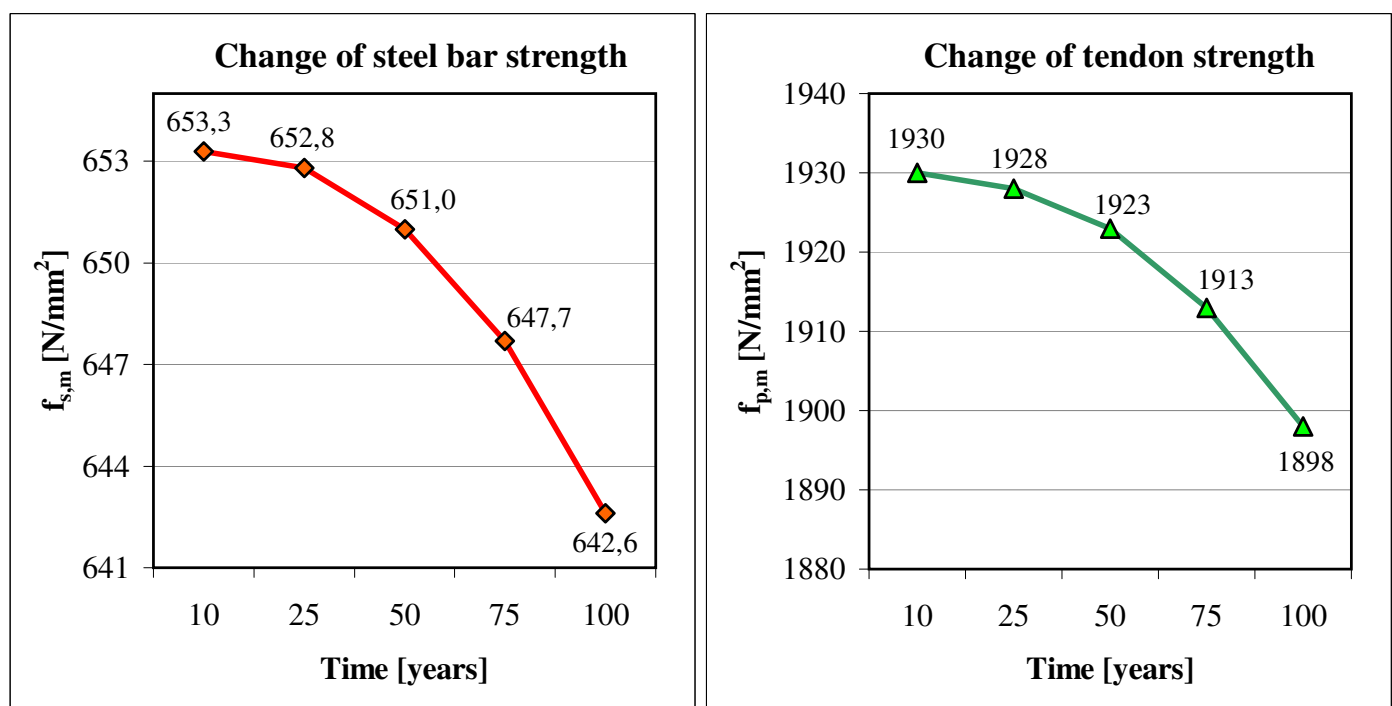

Fig. 3. Change of the mean value of strength in case of different materials in time

Fig. 4. Change of cross-sectional area of steel bars in time at different relative humidity levels
Side view

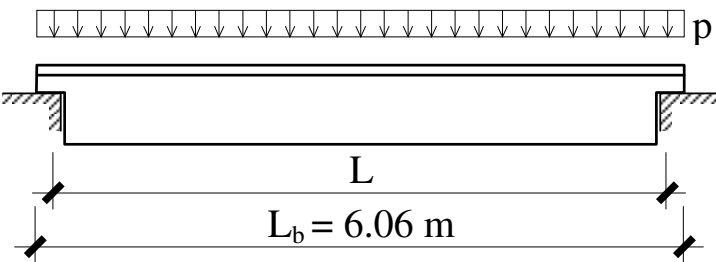

Concrete: $\mathrm{C} 40 / 50$

Steel bars: $4 \emptyset 16+2 \emptyset 16 B 60.50$

Prestressing strands: $8+2$ Fp-100/1770 R2
Cross-section

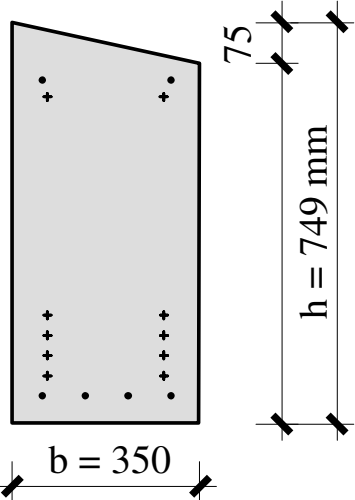

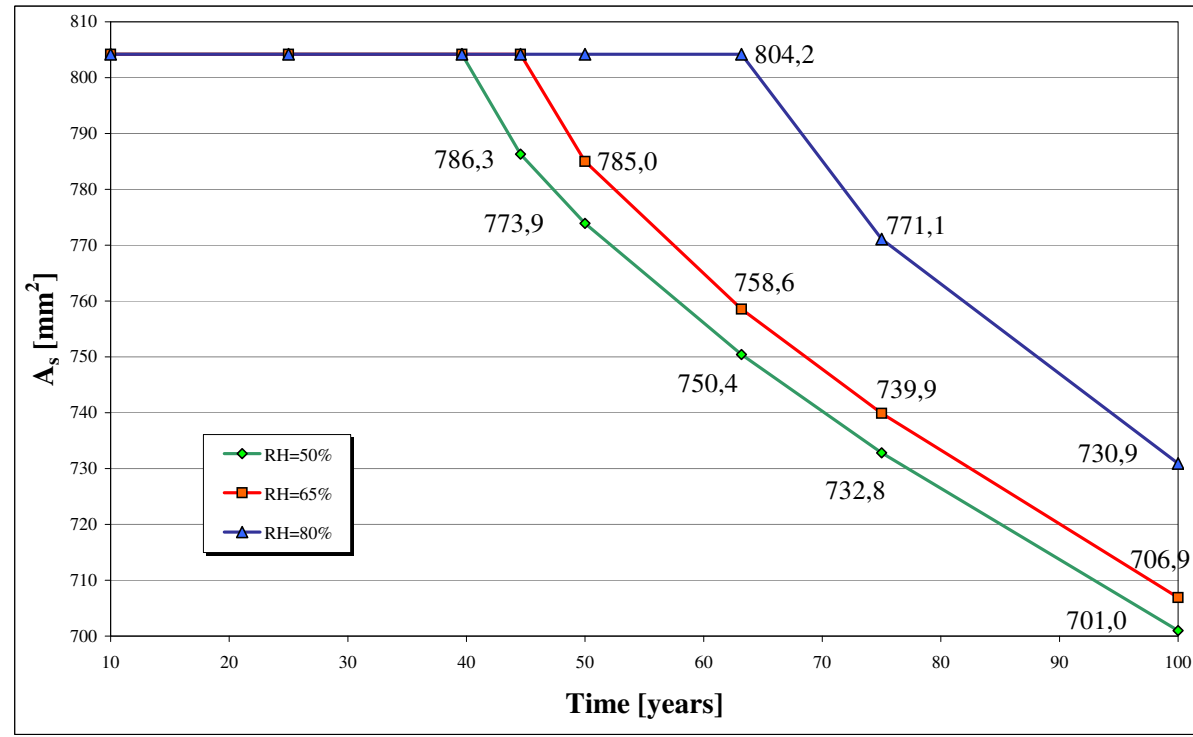




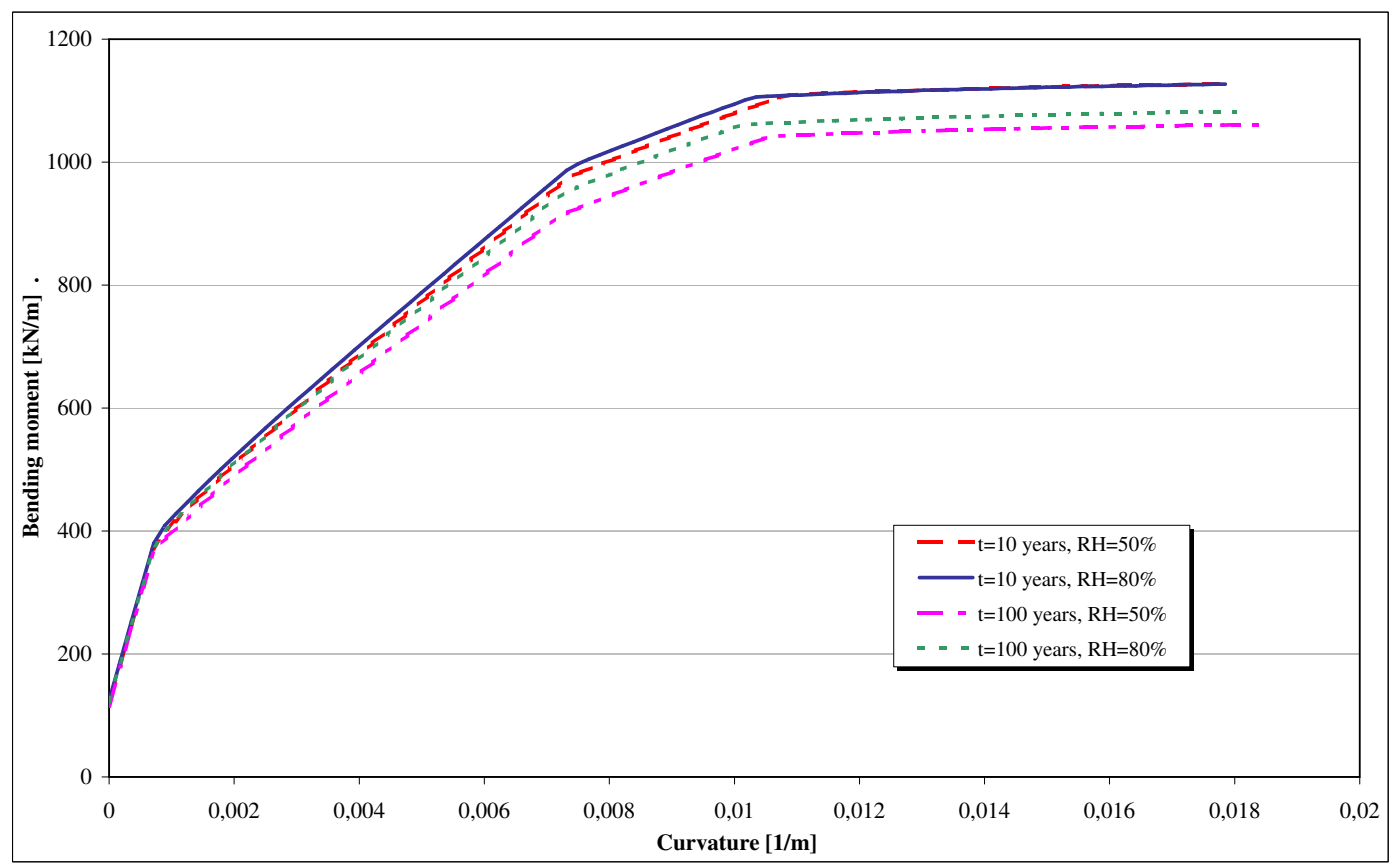

Fig. 5. Mean values of bending moment - curvature diagrams for beam type " 4700 " at different ages and humidity levels

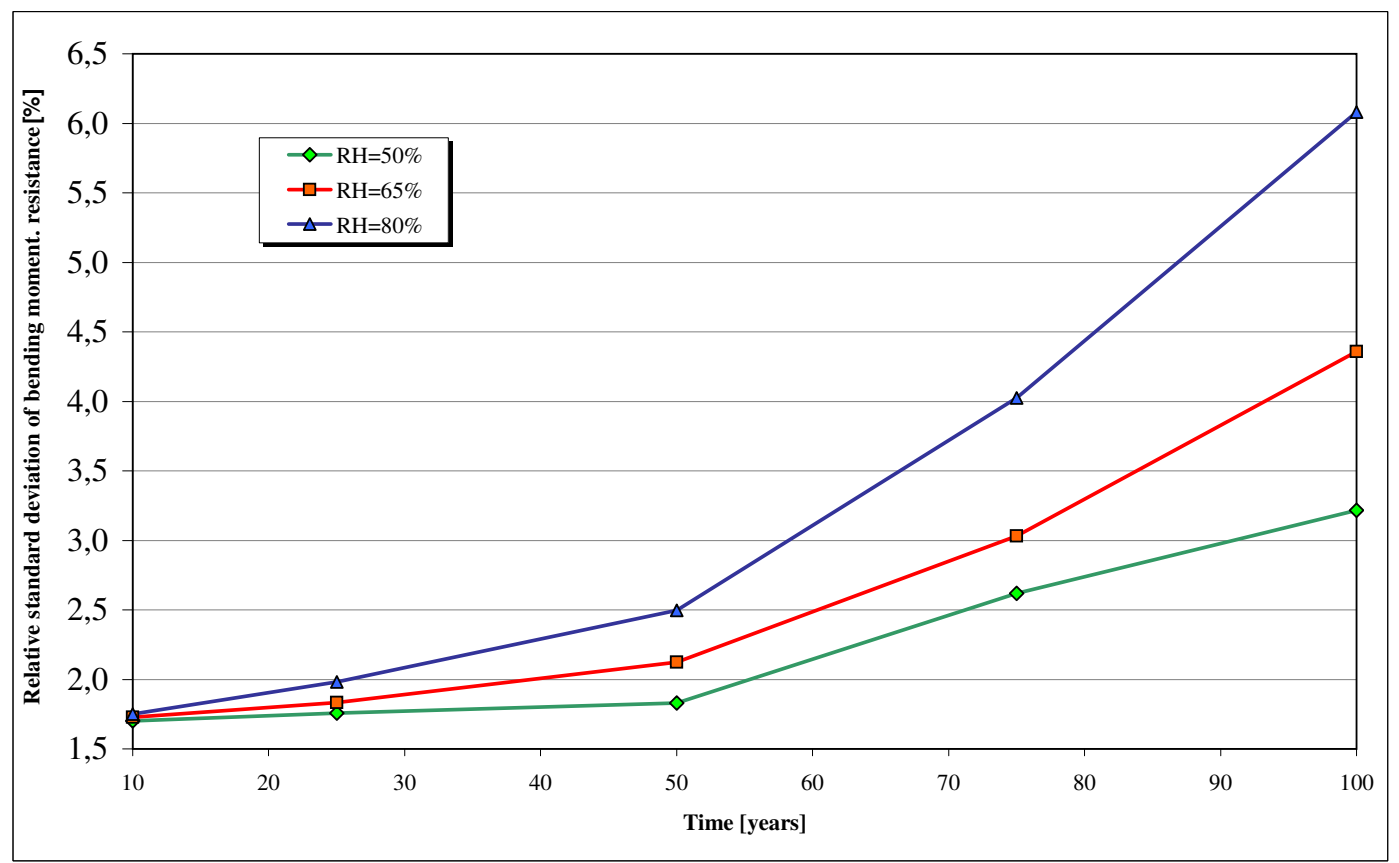

Fig. 6. Standard deviation of bending moment resistance in case of beam type " 4700 "

ing to the equation (1). Corrosion of steel bars inside the beam starts after 44.5 years in case of a relative ambient humidity of $R H=65 \%$. After 100 years, the amount of area loss of steel bars is about $13.8 \%$. The effect of the ambient relative humidity on the process of carbonation induced corrosion is demonstrated in Fig. 4. In case of lower humidity levels, the process of carbonation is faster so the corrosion of steel bars starts earlier. Higher levels of humidity result in slower carbonation thus corrosion starts later. However higher level of humidity also means higher rate of corrosion after the depassivation. The shape of the function is similar for the corrosion of prestressing tendons, but they start to corrode after 79.7 years only due to the larger concrete cover on them. Changes of the process parameters described above were considered during the calculation of the mean value of bending moment resistance over a time period of 100 years. The regulations of the relevant Eurocode 2 standard [5] were used for the determination of structural resistance. The effect of elapsed time and humidity level on the mean resistance of the cross-section is demonstrated by the corresponding bending moment-curvature diagrams (Fig. 5). It can be stated that the mean value of structural resistance decreases with the decrease of humidity level and progress of time. The rate of the decrease of the mean bending moment capacity was about $4-6 \%$ in case of the beam " 4700 " depending on the value of relative humidity. The rotation capacity of the beam is slightly increases as time is passing by. In case of humidity level $R H=50 \%$ the initial 
effective prestressing stress was $1135 \mathrm{~N} / \mathrm{mm}^{2}$ and this value decreased to $1117 \mathrm{~N} / \mathrm{mm}^{2}$ after 100 years. The corresponding initial and final values of effective prestressing were $1182 \mathrm{~N} / \mathrm{mm}^{2}$ and $1163 \mathrm{~N} / \mathrm{mm}^{2}$ in case of $R H=80 \%$ humidity level.

The effect of elapsed time and humidity level on the standard deviation of bending moment resistance is demonstrated in Fig. 6. After 100 years the decrease of relative standard deviation is about 200-350\% depending on the humidity level.

Calculated mean values and standard deviations of structural resistance were used for the determination of the probability of failure as a function of time for the given prefabricated member. Corresponding failure probability values were used for the durability design and life span estimation of the analysed beams [8]. Results of numerical analysis were also compared to the Eurocode 2 standard [5]. According to the calculations, the maximum mean value of the initial imposed load was about $10 \%$ higher than the value obtained from calculations according to Eurocode 2 (the same safety level was used in both cases). It means that more economical design can be achieved by the use of the implemented design method compared to Eurocode 2.

\section{Conclusions}

A method for the calculation of flexural resistance of pre-cast concrete members as a function of time and relative ambient humidity was presented. The implemented method is considering the creep and shrinkage of concrete, relaxation as well as the carbonation induced corrosion of steel bars and prestressing tendons. It could be generally stated that the mean value of structural resistance decreases with the decrease of humidity level and progress of time. The decrease of the mean value of bending moment capacity was about $4-6 \%$ in case of the examined beam types over a period of 100 years. The relative standard deviation of bending resistance increases in time. The rate of this increase is about $200-350 \%$ depending on the relative ambient humidity level. Mean values and standard deviations of flexural resistance obtained by the introduced analysis were used for the purposes of durability design and life span estimation of appropriate structural members $[8]$. The application of the presented design method results in a more economic design (higher load carrying capacity or smaller member sizes) of the examined pre-cast, prestressed concrete beams than the use of the relevant Eurocode 2 standard. The use of the method was demonstrated by a numerical example.

\section{References}

1 Almási J, Application of mathematical statistics in the analysis of R. C. and P. C. structures by the method of Finite Elements, Proceedings of the FIP VIII. Congress, London, 1978, pp. 1-14.

2 Augusti G, Ciampoli Marcello, Performance-Based Design in risk assessment and reduction, Probabilistic Engineering Mechanics 23 (2008), no. 4, 496-508, DOI DOI:10.1016/j.probengmech.2008.01.007.

3 Balázs LGy, Durability and methods for its improvement, Proceedings of the Congress "Durability of concrete structures", 2008, pp. 7-19.
4 Biondini F, Frangopol DM, Malerba PG, Uncertainty effects on lifetime structural performance of cable-stayed bridges, Probabilistic Engineering Mechanics 23 (2008), no. 4, 509-522, DOI DOI:10.1016/j.probengmech.2008.01.008.

5 Eurocode 2 (EN 1992-1-1): Design of concrete structures - Part 1: General rules and rules for buildings.

6 Eibl J, Schmidt-Hurtienne B, Grundlagen für ein neues Sicherheitskonzept, Bautechnik 72 (1996), no. 8, 501-506.

7 Koris K, Concrete Almanac 1998/1999, Hungarian Association for Building Material Industry, 1998.

$8 \ldots$, Durability-design of pre-cast concrete members, Proceedings of the CCC 2007 Congress "Innovative materials and technologies for concrete structures", 2007, pp. 407-412.

9 , Probabilistic approach for the durability design of prefabricated concrete members, Concrete Structures 10 (2009), 41-48.

10 Krätzig WB, Petryna Yuri S, Structural damage and life-time estimates by nonlinear FE simulation, Engineering Structures 27 (2005), no. 12, 17261740, DOI DOI:10.1016/j.engstruct.2005.04.015.

11 Lawrence MA, Computational Mechanics of Probabilistic and Reliability Analysis (Liu WK, ed.), Elmepress International, 1989.

12 Liu WK, Besterfield GH, Belytschko T, Variational Approach to Probabilistic Finite Elements, Journal of Engineering Mechanics 114 (1998), no. 12, 2115-2133, DOI DOI:10.1061/(ASCE)07339399(1988)114:12(2115).

13 Lógó J, Ghanemi M, Vásárhelyi A, Stochastic compliance constrained topology optimization based on optimality criteria method, Periodica Polytechnica, Civil Engineering 51 (2007), no. 2, 5-10, DOI DOI:10.3311/pp.ci.2007-2.02.

14 Lógó J, Kaliszky S, Ghanemi M, Topology Optimization Using Probabilistic Compliance Constraints, Proceedings of the Eighth International Conference on Computational Structures Technology, 2006, pp. 1-13.

15 Melchers RE, Structural reliability analysis and prediction, John Wiley \& Sons, 1999.

16 Mistéth E, Design theory, Akadémiai kiadó, 2001.

17 Model Code for Service Life Design, fib bulletin 34, Sprint-Digital-Druck, 2006.

18 Postek E, Reliability algorithm for reinforced concrete structures, an application, Proceedings of the AMAS Workshop RBO'02 Reliability-Based Design and Optimisation, 2002 September, pp. 303-318.

19 Zhao Dong-bing, Fan Li-chu, Numerical analysis of carrying capacity deterioration and repair demand of existing reinforced concrete bridge, Proceedings of the Fifth international conference on current and future trends in Bridge design, construction and maintenance, 2007 September, pp. 173-179. 